\title{
Mild parenchymal lung disease and/or low diffusion capacity impacts survival and treatment response in patients diagnosed with idiopathic pulmonary arterial hypertension
}

\author{
Robert A. Lewis ${ }^{1,2}$, A.A. Roger Thompson ${ }^{1,2}$, Catherine G. Billings ${ }^{1}$, \\ Athanasios Charalampopoulos ${ }^{1}$, Charlie A. Elliot ${ }^{1}$, Neil Hamilton ${ }^{1}$, \\ Catherine Hill ${ }^{3}$, Judith Hurdman ${ }^{1}$, Smitha Rajaram ${ }^{3}$, Ian Sabroe ${ }^{1,2}$, \\ Andy J. Swift ${ }^{3,4}$, David G. Kiely $\mathbb{1}^{1,2,4}$ and Robin Condliffe ${ }^{1,2}$
}

Affiliations: 'Sheffield Pulmonary Vascular Disease Unit, Royal Hallamshire Hospital, Sheffield, UK. ${ }^{2}$ Dept of Infection, Immunity and Cardiovascular Disease, University of Sheffield, Sheffield, UK. ${ }^{3}$ Dept of Academic Radiology, University of Sheffield, Sheffield, UK. ${ }^{4}$ Insigneo Institute for in silico Medicine, University of Sheffield, Sheffield, UK.

Correspondence: Robin Condliffe, Sheffield Pulmonary Vascular Disease Unit, Royal Hallamshire Hospital, Sheffield, S10 2JF, UK. E-mail: robin.condliffeanhs.net

@ERSpublications

Patients with IPAH who have mild parenchymal lung disease have significantly worse outcomes, in terms of survival and treatment response, when compared to patients with IPAH who do not have evidence of parenchymal lung disease http://bit.ly/3agkYn0

Cite this article as: Lewis RA, Thompson AAR, Billings CG, et al. Mild parenchymal lung disease and/or low diffusion capacity impacts survival and treatment response in patients diagnosed with idiopathic pulmonary arterial hypertension. Eur Respir J 2020; 55: 2000041 [https://doi.org/10.1183/13993003.00041-2020].

ABSTRACT There are limited published data defining survival and treatment response in patients with mild lung disease and/or reduced gas transfer who fulfil diagnostic criteria for idiopathic pulmonary arterial hypertension (IPAH).

Patients diagnosed with IPAH between 2001 and 2019 were identified in the ASPIRE (Assessing the Spectrum of Pulmonary Hypertension Identified at a Referral Centre) registry. Using prespecified criteria based on computed tomography (CT) imaging and spirometry, patients with a diagnosis of IPAH and no lung disease were termed $\mathrm{IPAH}_{\text {no-LD }}(\mathrm{n}=303)$, and those with minor/mild emphysema or fibrosis were described as IPAH $\mathrm{mild}_{-\mathrm{LD}}(\mathrm{n}=190)$.

Survival was significantly better in $\mathrm{IPAH}_{\text {no-LD }}$ than in $\mathrm{IPAH}_{\text {mild-LD }}$ (1- and 5-year survival 95\% and 70\% versus $78 \%$ and $22 \%$, respectively; $\mathrm{p}<0.0001$ ). In the combined group of $\mathrm{IPAH}_{\text {no-LD }}$ and $\mathrm{IPAH}_{\text {mild-LD, }}$ independent predictors of higher mortality were increasing age, lower diffusing capacity of the lung for carbon monoxide $\left(D_{\text {LCO }}\right)$, lower exercise capacity and a diagnosis of $\mathrm{IPAH}_{\text {mild-LD }}($ all $\mathrm{p}<0.05$ ). Exercise capacity and quality of life improved (both $\mathrm{p}<0.0001$ ) following treatment in patients with $\mathrm{IPAH}_{\text {no-LD }}$, but not $\mathrm{IPAH}_{\text {mild-LD. }}$ A proportion of patients with $\mathrm{IPAH}_{\mathrm{no}-\mathrm{LD}}$ had a $D_{\mathrm{LCO}}<45 \%$; these patients had poorer survival than patients with $D_{\mathrm{LCO}} \geqslant 45 \%$, although they demonstrated improved exercise capacity following treatment.

The presence of even mild parenchymal lung disease in patients who would be classified as IPAH according to current recommendations has a significant adverse effect on outcomes. This phenotype can be identified using lung function testing and clinical CT reports. Patients with IPAH, no lung disease and severely reduced $D_{\text {LCO }}$ may represent a further distinct phenotype. These data suggest that randomised controlled trials of targeted therapies in patients with these phenotypes are required.

This article has an editorial commentary: https://doi.org/10.1183/13993003.00606-2020

This article has supplementary material available from erj.ersjournals.com

Received: 4 Dec 2019 | Accepted after revision: 16 Feb 2020

Copyright OERS 2020. This version is distributed under the terms of the Creative Commons Attribution Licence 4.0. 


\section{Introduction}

Idiopathic pulmonary arterial hypertension (IPAH) is a rare condition (estimated incidence $<5$ million cases per year) defined haemodynamically as mean pulmonary arterial pressure (mPAP) $>20 \mathrm{mmHg}$, left atrial pressure $\leqslant 15 \mathrm{mmHg}$ and pulmonary vascular resistance $>3$ Wood units $[1,2]$. It is defined clinically as the absence of conditions or risk factors associated with the development of precapillary pulmonary hypertension, including connective tissue disease, congenital heart disease, chronic thromboembolic disease and lung disease [3]. Several medical therapies have been shown to improve haemodynamics, exercise capacity and clinical events, and survival has improved significantly over the past three decades [4-6]. Chronic lung disease-associated pulmonary hypertension (CLD-PH) is common; 90\% of patients with severe COPD have a mPAP $>20 \mathrm{mmHg}$ [7]. Significant pulmonary hypertension in association with lung disease is less common; $\leqslant 5 \%$ of COPD patients have $\mathrm{mPAP} \geqslant 35 \mathrm{mmHg}$ [8].

Mild lung disease may be present in patients with severe precapillary haemodynamics. This can create diagnostic uncertainty as to whether a patient has group 1 (pulmonary arterial hypertension (PAH)) or group 3 (CLD-PH) disease. The recent 6th World Symposium on Pulmonary Hypertension (WSPH) suggested that patients with coexisting lung disease should be diagnosed with PAH when pulmonary hypertension is moderate-severe, when only modest spirometric or parenchymal abnormalities are present and when diffusion capacity of the lung for carbon monoxide $\left(D_{\mathrm{LCO}}\right)$ is low with respect to obstructive or restrictive lung function [7].

There are few data defining survival and treatment response in patients with mild lung disease who fulfil the diagnostic criteria for IPAH suggested by the 6th WSPH. We hypothesised that even mild lung disease and/ or low gas transfer have a negative effect on outcomes in patients with a diagnosis of IPAH. Therefore, we performed a study of characteristics, survival and response to therapy of patients who had been assigned a diagnosis of IPAH at a large pulmonary hypertension referral centre over an 18 -year period.

\section{Methods}

Patients who had been assigned a diagnosis of IPAH or heritable PAH or CLD-PH between February 2001 and January 2019 at our centre were identified from the ASPIRE (Assessing the Spectrum of Pulmonary Hypertension Identified at a Referral Centre) registry, a database consisting of consecutive patients referred to the Sheffield Pulmonary Vascular Disease Unit (Sheffield, UK), who undergo multimodality assessment and multidisciplinary team discussion, as previously described [9]. Radiology images and reports, lung function tests, pulmonary haemodynamics and clinical correspondence were retrieved, blinded to outcomes. Computed tomography (CT) images had been reported at the time of diagnosis by experienced pulmonary vascular radiologists, blinded to haemodynamics and spirometry, using a qualitative assessment of the extent of parenchymal lung disease: none, minor, mild, moderate or severe. In the absence of moderate to severely abnormal spirometry (defined as forced expiratory volume in $1 \mathrm{~s}\left(\mathrm{FEV}_{1}\right)<60 \%$ and/or forced vital capacity $(\mathrm{FVC})<70 \%$ ), patients with a diagnosis of IPAH or heritable PAH who had no parenchymal lung disease were termed $\mathrm{IPAH}_{\text {no-LD }}$ while those who had minor or mild emphysema or fibrosis on their original CT

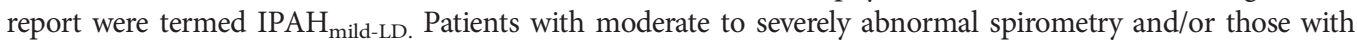
moderate or severe parenchymal lung disease were defined as CLD-PH. Patients with pulmonary hypertension caused by respiratory disease other than COPD, emphysema or interstitial lung disease (ILD) were excluded. In addition, patients with two or more radiological features of possible pulmonary veno-occlusive disease (PVOD: centrilobular ground-glass opacities, mediastinal lymphadenopathy and interlobular septal lines) were excluded [10]. Smoking status and history were retrieved from clinical notes.

Quality of life was assessed by emPHasis-10 score [11] (scored out of 50; lower score represents lower symptom burden).

\section{Mortality data}

Mortality data were obtained from systems linked to the National Health Service Personal Demographics Service (PDS), which is updated when a death is registered in the UK. Patients who emigrated ( $n=3$ ) were excluded, as were patients without a record on the PDS $(n=2)$. Patients undergoing lung transplantation were censored at the time of surgery, and mortality data were collected using a census date of May 31, 2019.

\section{Follow-up}

Two follow-up time points were used to assess treatment response: first follow-up beyond 90 days of diagnosis and first follow-up between 9 and 15 months in patients receiving oral combination therapy within 6 months of diagnosis. The latter time point was used to enable comparison between patients who had received a similar therapeutic approach. 


\section{Statistics}

Statistical analysis was performed using SPSS (v25; IBM, Armonk, NY, USA) and GraphPad Prism (v8; GraphPad, La Jolla, CA, USA). Unless otherwise specified, continuous data are presented as mean \pm SD (compared using paired/unpaired t-tests) or median (interquartile range) for nonparametric data (compared using Wilcoxon signed-rank/Mann-Whitney U-tests). Frequencies were compared using the Chi-squared test. Multivariate Cox regression was performed in a forward direction on parameters with a p-value $<0.2$ at univariate analysis. To allow comparison at univariate and multivariate analysis, continuous variables were scaled to the mean. For other statistical tests, a p-value of $<0.05$ was considered significant. Kaplan-Meier survival curves were compared using the log-rank test, truncated at 5 years. Where appropriate, $95 \%$ confidence intervals were derived for median values using a bootstrap resampling technique.

\section{Ethics}

Ethical approval was granted by Sheffield Teaching Hospitals NHS Foundation Trust (STH14169) and approved by the National Research Ethics Service (16/YH/0352).

\section{Results}

Of 5643 patients diagnosed with all forms of pulmonary hypertension, 493 incident patients were identified who had a diagnosis of either idiopathic or heritable PAH (hereafter grouped as IPAH, who formed the main study population) (figure 1). Following reassessment of patients assigned a diagnosis of

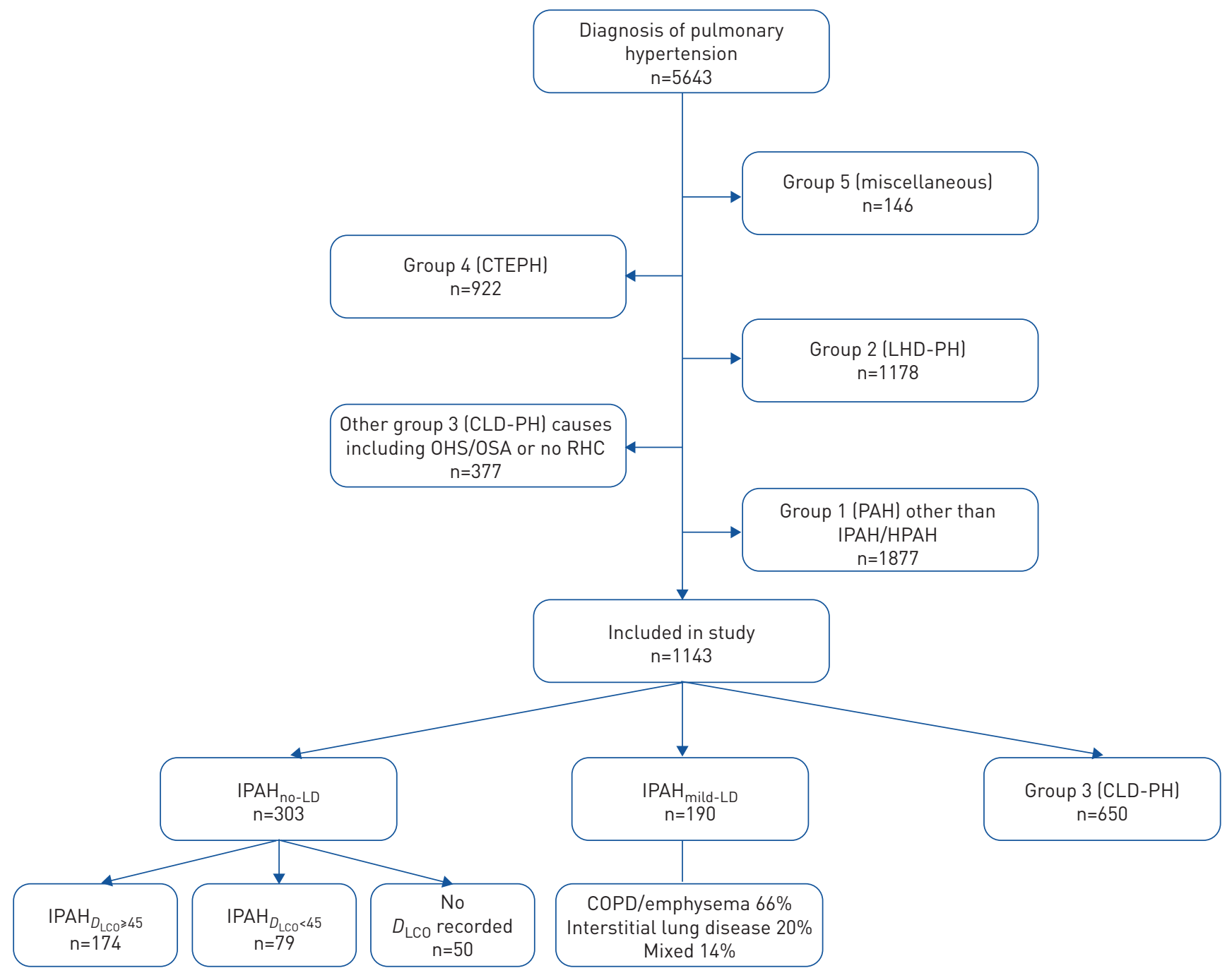

FIGURE 1 Flow chart demonstrating selection of patients for participation in study. CTEPH: chronic thromboembolic pulmonary hypertension; LHD-PH: pulmonary hypertension due to left heart disease; CLD-PH: chronic lung disease-associated pulmonary hypertension; OHS: obesity hypoventilation syndrome; OSA: obstructive sleep apnoea; RHC: right heart catheterisation; PAH: pulmonary arterial hypertension; IPAH: idiopathic PAH; HPAH: heritable PAH; IPAH ${ }_{n o-L D}$ : IPAH with no lung disease; IPAH mild-LD: IPAH with mild lung disease; IPAH $\mathrm{D}_{\mathrm{LCO}_{0} \geqslant 45}$ IPAH with no lung disease with $D_{\mathrm{LCO}} \geqslant 45 \%$ pred; IPAH $\mathrm{PLCO}<45_{1}$ IPAH with no lung disease with $D_{\mathrm{LCO}}<45 \%$ pred. 
IPAH, 303 had no evidence of parenchymal lung disease ( $\left.\mathrm{IPAH}_{\text {no-LD }}\right)$ while 190 had minor or mild parenchymal lung disease ( $\mathrm{IPAH}_{\text {mild-LD }}$ ). Baseline right heart catheterisation data were available in $98 \%$, spirometry in $97 \%$ and $D_{\mathrm{LCO}}$ in $83 \%$ of patients with $\mathrm{IPAH}_{\text {no-LD }}$ and $\mathrm{IPAH}_{\text {mild-LD. }}$

Comparison of IPAH $H_{\text {no-LD }}$ versus IPAH $H_{\text {mild-LD }}$

Patients with $\mathrm{IPAH}_{\text {no-LD }}$ were younger (mean age 53 versus 70 years; $\mathrm{p}<0.0001$ ), had a female predominance ( $73 \%$ versus $47 \% ; \mathrm{p}<0.0001$ ), a higher mean $\mathrm{mPAP}$ and mixed venous oxygen saturations (mPAP $55 \mathrm{mmHg}$ versus $50 \mathrm{mmHg}$, mixed venous oxygen saturation $\left(S_{\mathrm{vO}_{2}}\right) 60 \%$ versus $62 \%$; both $\mathrm{p}<0.05$ ) and were less likely to have a smoking history than patients with $\operatorname{IPAH}_{\text {mild-LD }}(\mathrm{p}<0.0001)$ (table 1$)$. Spirometric volumes were well preserved in patients with $\mathrm{IPAH}_{\text {no-LD }}$ and $\mathrm{IPAH}_{\text {mild-LD }}$. Patients with $\mathrm{IPAH}_{\text {no-LD }}$ had significantly better survival than patients who had $\mathrm{IPAH}_{\text {mild-LD }}$ (1- and 5-year survival $95 \%$ and $70 \%$ versus $78 \%$ and $22 \%$, respectively; $\mathrm{p}<0.0001$ ) (figure 2 ). When patients with $\mathrm{IPAH}_{\mathrm{no}-\mathrm{LD}}$ and $\mathrm{IPAH}_{\text {mild-LD }}$ were analysed together in a multivariate model, independent predictors of higher mortality were increasing age, lower $D_{\text {LCO }} \%$ predicted, lower incremental shuttle walking test distance (ISWD) and a diagnosis of $\mathrm{IPAH}_{\text {mild-LD }}$ (table 2). In view of the different forms of parenchymal lung disease encompassed by $\mathrm{IPAH}_{\text {mild-LD, }}$ this multivariate model was reanalysed using data for the emphysema or interstitial lung disease subtypes separately. Increasing age, lower ISWD and a diagnosis of IPAH $_{\text {mild-LD }}$ remained as independent predictors of mortality. There was no significant difference in survival between

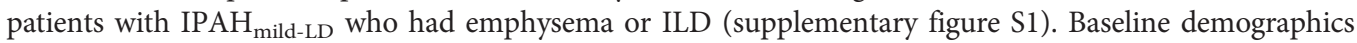
and haemodynamics of these groups were also very similar (supplementary table S1). Lung function data for subtypes of $\mathrm{IPAH}_{\text {mild-LD }}$ are also shown in supplementary table S1.

TABLE 1 Baseline demographics and maximal treatment data

\begin{tabular}{|c|c|c|c|}
\hline & IPAH $_{\text {no-LD }}$ & IPAH $_{\text {mild-LD }}$ & p-value \\
\hline Subjects $\mathrm{n}$ & 303 & 190 & \\
\hline Female & 73 & 47 & $<0.0001$ \\
\hline Age years & $53 \pm 17$ & $70 \pm 10$ & $<0.0001$ \\
\hline WHO FC I/II/III/IV & $0 / 21 / 60 / 19$ & $0 / 9 / 56 / 35$ & \\
\hline BMI $\mathrm{kg} \cdot \mathrm{m}^{-2}$ & $29 \pm 6$ & $28 \pm 6$ & 0.15 \\
\hline mRAP mmHg & $11 \pm 6$ & $11 \pm 5$ & 0.39 \\
\hline mPAP $\mathrm{mmHg}$ & $55 \pm 13$ & $50 \pm 9$ & $<0.0001$ \\
\hline PAWP mmHg & $10 \pm 3$ & $11 \pm 3$ & 0.10 \\
\hline PVR WU & $11.9 \pm 5.8$ & $11.1 \pm 4.5$ & 0.10 \\
\hline $\mathrm{S}_{\mathrm{vO}_{2}} \%$ & $62 \pm 9$ & $59 \pm 9$ & 0.02 \\
\hline Cardiac output L.min ${ }^{-1}$ & $4.3 \pm 1.6$ & $4.0 \pm 1.4$ & 0.04 \\
\hline Cardiac index $L \cdot \min ^{-1} \cdot \mathrm{m}^{-2}$ & $2.3 \pm 0.8$ & $2.2 \pm 0.7$ & 0.07 \\
\hline FEV $_{1} \%$ pred & $89 \pm 15$ & $89 \pm 17$ & 0.64 \\
\hline FVC \% pred & $100 \pm 17$ & $103 \pm 18$ & $<0.05$ \\
\hline $\mathrm{FEV}_{1} / \mathrm{FVC}$ & $75 \pm 9$ & $68 \pm 8$ & $<0.0001$ \\
\hline$D_{\text {Lco }} \%$ pred & $56 \pm 20$ & $30 \pm 13$ & $<0.0001$ \\
\hline ISWD m & $210(80,360)$ & $80(40,180)$ & $<0.0001$ \\
\hline Current smokers & 40 & 82 & $<0.0001$ \\
\hline Smoking history pack-years & $25 \pm 17$ & $32 \pm 18$ & 0.03 \\
\hline \multicolumn{4}{|l|}{ Maximal treatment ${ }^{\#}$} \\
\hline None & 1 & 1 & \\
\hline $\mathrm{CCB}$ & 5 & 1 & \\
\hline Oral monotherapy & 19 & 34 & \\
\hline Combination oral & 44 & 50 & \\
\hline Prostanoid \pm oral & 31 & 14 & \\
\hline
\end{tabular}

Data are presented as $\%$, mean \pm SD or median (interquartile range), unless otherwise stated. IPAH:

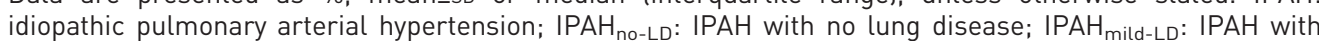
mild lung disease; WHO FC: World Health Organization functional class; BMI: body mass index; mRAP: mean right atrial pressure; mPAP: mean pulmonary arterial pressure; PAWP: pulmonary arterial wedge pressure; PVR: pulmonary vascular resistance; WU: Wood units; $\mathrm{S}_{\mathrm{vo}_{2}}$ : mixed venous oxygen saturation; $\mathrm{FEV}_{1}$ : forced expiratory volume in $1 \mathrm{~s} ; \mathrm{FVC}$ : forced vital capacity; $D_{\mathrm{LCO}}$ : diffusing capacity of the lung for carbon monoxide; ISWD: incremental shuttle walking test distance; CCB: calcium-channel blockers. ${ }^{\#}$ : received during the study. 


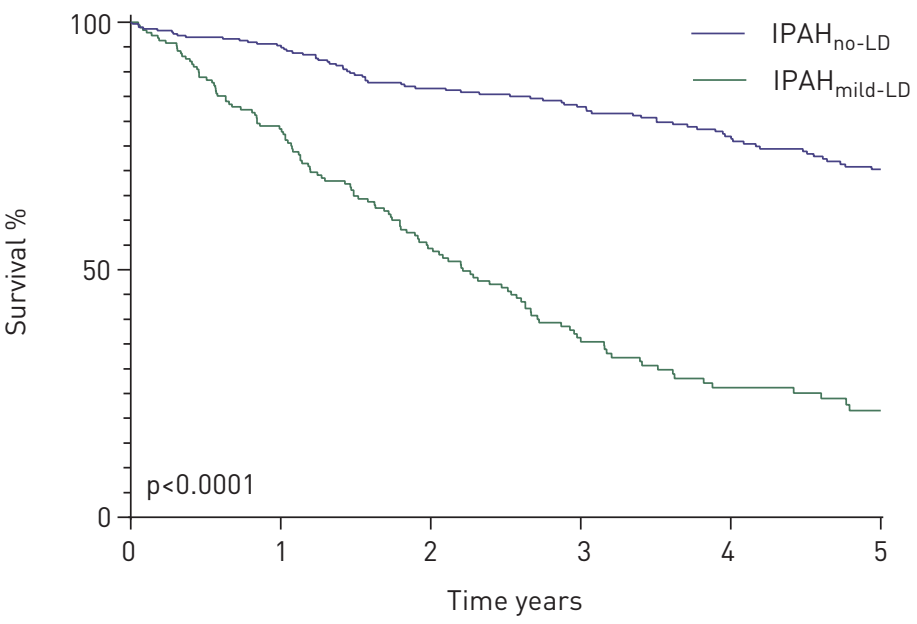

At risk n
IPAH $_{\text {no-LD }}$
IPAH $_{\text {mild-LD }}$

303

265

218

191

155

128

PAH

190

138

85

46

27

18

FIGURE 2 Survival from diagnosis in idiopathic pulmonary arterial hypertension with no lung disease (IPAH no-LD $_{\text {l }}$ and with mild lung disease (IPAH mild-LD $_{\text {. }}$.

Effect of $\mathrm{D}_{L C O}$ on survival in IPAH ${ }_{\text {no-LD }}$

A bimodal distribution of $D_{\text {LCO }} \%$ predicted (modes 30,65$)$ was observed in patients with IPAH $_{\text {no-LD }}$ with an optimal cut-point of $45 \%$ (supplementary figure S2). Patients with $\mathrm{IPAH}_{\text {no-LD }}$ who had a $D_{\mathrm{LCO}}<45 \%$ pred (IPAH $\left.{ }_{D L C O<45}\right)$ were older (mean 65 versus 48 years), had a lower mPAP (51 versus $56 \mathrm{mmHg}$ ) and a lower $S_{\mathrm{vO}_{2}}(60 \%$ versus $63 \%)$ than patients with $D_{\mathrm{LCO}} \geqslant 45 \%$ predicted $\left(\mathrm{IPAH}_{\mathrm{D}_{\mathrm{LCO}} \geqslant 45}\right)($ all $\mathrm{p}<0.05)$. Detailed demographics are shown in supplementary table S2. Those with $\mathrm{IPAH}_{D \mathrm{LCO}<45}$ were more likely to have a history of smoking $(52 \%$ versus $36 \%$; $\mathrm{p}<0.05)$. There was no significant difference in lung volumes $\left(\mathrm{FEV}_{1}\right.$

TABLE 2 Univariate and multivariate Cox regression analysis of prognostic factors in patients with idiopathic pulmonary arterial hypertension with no lung disease (IPAH $\mathrm{Ho}_{\mathrm{LD}}$ ) or mild lung disease (IPAH mild-LD)

\begin{tabular}{|c|c|c|c|c|}
\hline & \multicolumn{2}{|c|}{ Univariate } & \multicolumn{2}{|c|}{ Multivariate } \\
\hline & Scaled HR & p-value & Scaled HR & p-value \\
\hline IPAH $_{\text {mild-LD }}$ (ref. IPAH ${ }_{\text {no-LD }}$ ) & 4.287 & $<0.0001$ & 2.168 & $<0.0001$ \\
\hline Age (years) & 2.320 & $<0.0001$ & 1.432 & 0.014 \\
\hline Sex (ref. female) & 1.549 & 0.001 & & \\
\hline Smoking history (ref. none) & 2.373 & $<0.0001$ & & \\
\hline WHO FC III and IV (ref. I and II) & 3.246 & $<0.0001$ & & \\
\hline FEV $_{1} \%$ pred & 0.995 & 0.945 & & \\
\hline FVC $\%$ pred & 1.072 & 0.328 & & \\
\hline $\mathrm{FEV}_{1} / \mathrm{FVC}$ & 0.767 & $<0.0001$ & & \\
\hline$D_{\text {Lco }} \%$ pred & 0.340 & $<0.0001$ & 0.739 & 0.039 \\
\hline mRAP (mmHg) & 1.239 & $<0.0005$ & & \\
\hline PVR (WU) & 0.999 & 0.986 & & \\
\hline$S_{\mathrm{vo}_{2}}(\%)$ & 0.740 & $<0.0001$ & & \\
\hline Cardiac index $\left(L \cdot \min ^{-1} \cdot \mathrm{m}^{-2}\right)$ & 0.788 & 0.003 & & \\
\hline ISWD (m) & 0.434 & $<0.0001$ & 0.559 & $<0.0001$ \\
\hline
\end{tabular}

For continuous variables, hazard ratios (HR) are scaled to the mean. ref: reference; WHO FC: World Health Organization functional class; $\mathrm{FEV}_{1}$ : forced expiratory volume in $1 \mathrm{~s}$; FVC: forced vital capacity; $D_{\mathrm{Lco}}$ : diffusing capacity of the lung for carbon monoxide; mRAP: mean right atrial pressure; PVR: pulmonary vascular resistance; WU: Wood units; $S_{\mathrm{vO}_{2}}$ : mixed venous oxygen saturation; ISWD: incremental shuttle walking test distance. 
$88 \%$ versus $91 \%$, FVC $100 \%$ versus $100 \%$; both $\mathrm{p}>0.05)$, but $\mathrm{FEV}_{1} / \mathrm{FVC}$ ratio was lower $(71 \%$ versus $76 \%$; $\mathrm{p}<0.0001)$ in patients with $\mathrm{IPAH}_{D \mathrm{LCO}<45}$. 1- and 5-year survival was significantly lower in patients with $\mathrm{IPAH}_{D \mathrm{LCO}<45}(86 \%$ and $45 \%$ versus $99 \%$ and $84 \%$; $\mathrm{p}<0.0001$ ) (figure 3); this survival difference persisted when adjusted for age.

\section{Response to treatment}

99\% of patients with $\mathrm{IPAH}_{\text {no-LD }}$ and $\mathrm{IPAH}_{\text {mild-LD }}$ received PAH therapy; treatment response data are shown in table 3 and figure 4 . Baseline ISWD was significantly higher in $\mathrm{IPAH}_{\text {no-LD }}$ than $\mathrm{IPAH}_{\text {mild-LD }}$ : median $210 \mathrm{~m}$ versus $80 \mathrm{~m}$ ( $\mathrm{p}<0.0001)$. There was no significant difference in time to follow-up between patients with $\mathrm{IPAH}_{\mathrm{no}-\mathrm{LD}}$ and $\mathrm{IPAH}_{\text {mild-LD }}$. At both first follow-up and at 1-year assessment in patients who received combination oral therapy within 6 months of diagnosis, patients with IPAH no-LD $_{2}$ demonstrated significant improvement with respect to ISWD and quality-of-life score $(p<0.0001)$, whereas patients with $\mathrm{IPAH}_{\text {mild-LD }}$ did not. In patients receiving oral combination therapy within 6 months of diagnosis, survival was significantly better in patients with $\mathrm{IPAH}_{\text {no-LD }}$ compared to patients with $\mathrm{IPAH}_{\text {mild-LD }}$ ( 1 - and 5 -year survival $98 \%$ and $74 \%$ versus $71 \%$ and $13 \%$; $<<0.0001$ ) (figure 5). Patients with $\mathrm{IPAH}_{\text {no-LD }}$ and $\mathrm{IPAH}_{\text {mild-LD }}$ who received oral combination therapy within 6 months of diagnosis and had 1-year follow-up data available had more severe haemodynamics than those who did not; haemodynamic and treatment data for all patients who had follow-up assessments available are displayed in supplementary table S3.

In the IPAH $\mathrm{In}_{\text {no-LD }}$ group, significant change $(\Delta)$ in ISWD was seen in patients with $\mathrm{IPAH}_{D \mathrm{LCO}<45}$ (median $\Delta+20 \mathrm{~m})$ and $\mathrm{IPAH}_{\mathrm{D}_{\mathrm{LCO}} \geqslant 45}(\Delta+50 \mathrm{~m})$ who received treatment; both $\mathrm{p}<0.05$. Baseline emPHasis-10 scores were significantly higher in patients with $\mathrm{IPAH}_{D \mathrm{LCO}<45}$ than in patients with $\mathrm{IPAH}_{\mathrm{D}_{\mathrm{LCO}} \geqslant 45}$ (median 38 versus 27; $\mathrm{p}<0.01)$. Median change in emPHasis-10 at follow-up was not significant in patients with $\mathrm{IPAH}_{D \mathrm{LCO}<45}(\Delta \mathrm{emPHasis}-10-4 ; \mathrm{p}=0.08)$ but was significant in patients with $\operatorname{IPAH}_{\mathrm{D}_{\mathrm{ICO}} \geqslant 45}(\Delta \mathrm{emPHasis}-10$ $-4 ; \mathrm{p}<0.05)$.

\section{Discussion}

In the current study we reassessed a large number of patients who had been assigned a diagnosis of IPAH at a large pulmonary hypertension referral centre. By using radiology reports and lung function from the time of diagnosis we have identified phenotypes of IPAH with different characteristics, response to therapy and survival. Specifically, we have demonstrated that the presence of even mild parenchymal lung disease in patients who have been diagnosed with IPAH $\left(\mathrm{IPAH}_{\text {mild-LD }}\right)$ is associated with a distinct clinical picture (well-preserved spirometry, low $D_{\mathrm{LCO}} \%$ pred and severe pulmonary hypertension) and has a large negative effect on outcomes. In addition, we have observed that a proportion of patients with IPAH with no parenchymal lung disease and unremarkable spirometry have a low $D_{\text {LCO }}$. Differentiation of IPAH from CLD-PH represents a continual diagnostic challenge to all involved in the care of patients with

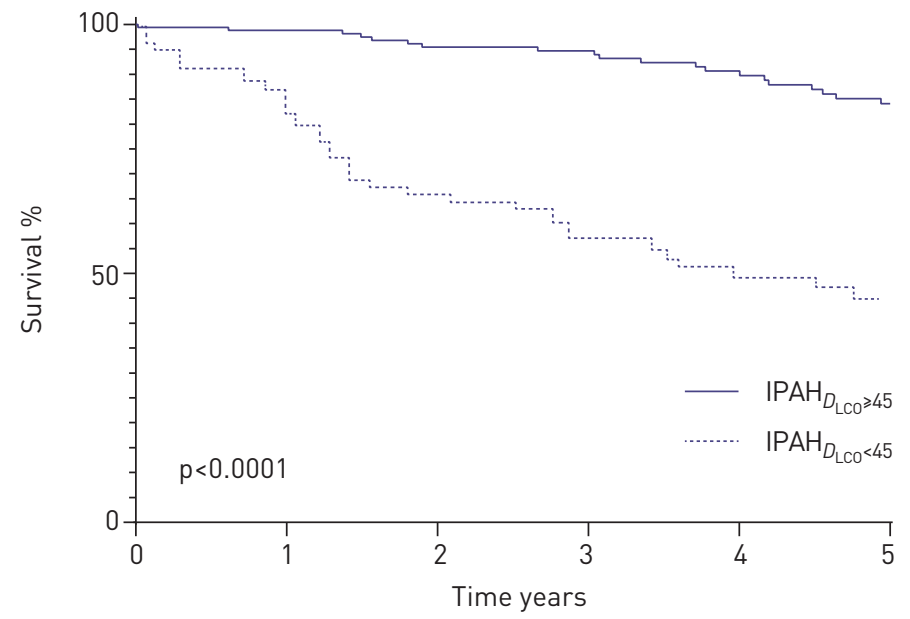

$\begin{array}{lcccccc}\text { At risk n } & & & & & \\ \mathrm{IPAH}_{D_{\mathrm{LC} 0} \geqslant 45} & 174 & 156 & 135 & 121 & 101 & 84 \\ \mathrm{IPAH}_{D_{\mathrm{LCO}}<45} & 79 & 62 & 42 & 32 & 24 & 17\end{array}$

FIGURE 3 Survival in idiopathic pulmonary arterial hypertension patients with no lung disease stratified by diffusing capacity of the lung for carbon monoxide $<45 \%$ pred (IPAH $\mathrm{HLCO}<45_{5}$ ) versus $\geqslant 45 \%$ pred (IPAH $\mathrm{D}_{\llcorner\mathrm{LCO} \geqslant 45}$ ). 
TABLE 3 Baseline and follow-up incremental shuttle walking test distance (ISWD) and emPHasis-10 quality-of-life score (E-10)

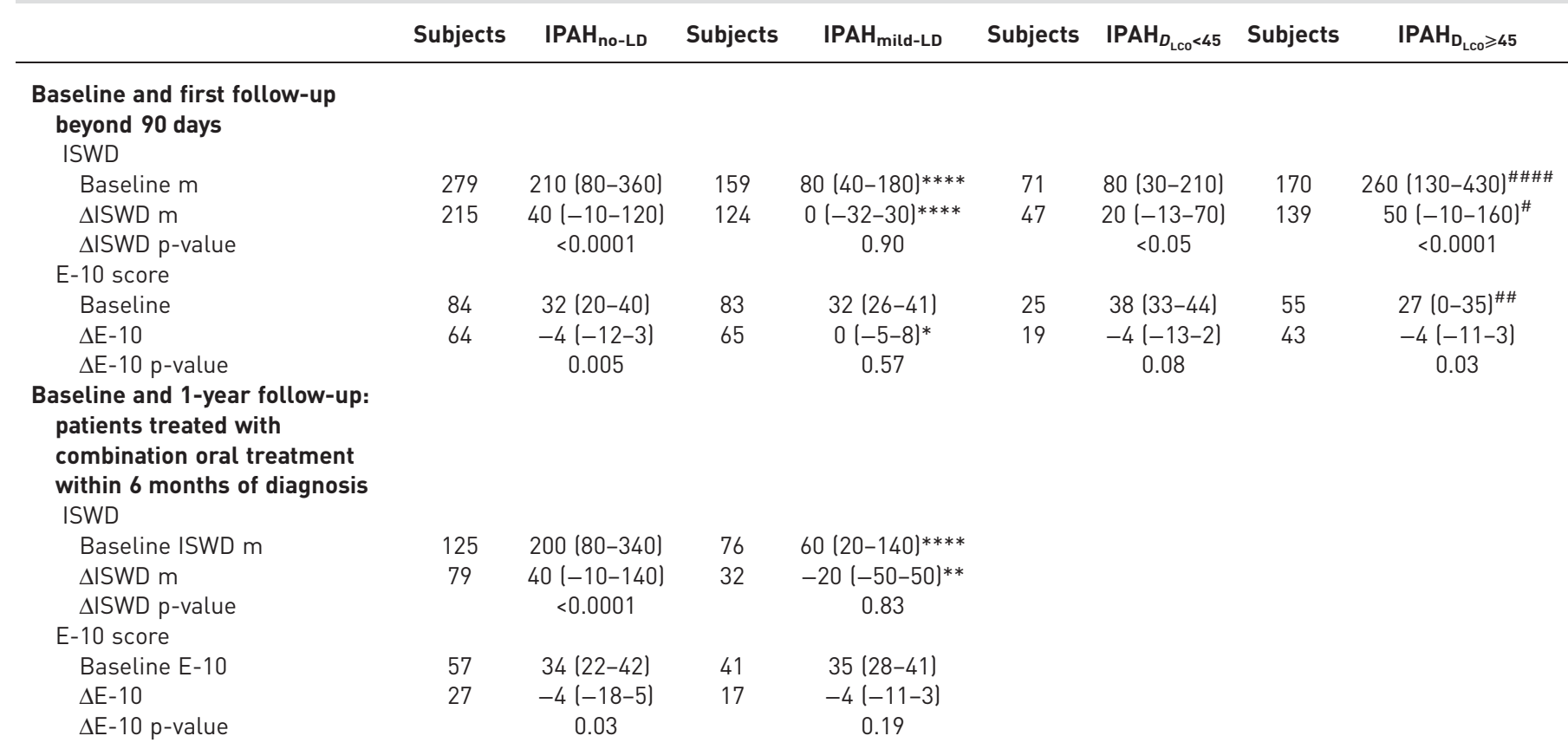

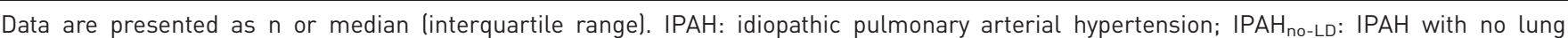
disease; IPAH $H_{\text {mild-LD }}$ IPAH with mild lung disease; IPAH $\mathrm{D}_{\mathrm{LCO}<45}$ : IPAH $\mathrm{IO}_{\mathrm{no}-\mathrm{LD}}$ with $D_{\mathrm{LCO}}<45 \%$ pred; IPAH $\mathrm{D}_{\mathrm{LCO}} \geqslant 45:$ IPAH $\mathrm{H}_{\mathrm{no}-\mathrm{LD}}$ with $D_{\mathrm{LCO}} \geqslant 45 \%$ pred; $\Delta$ :

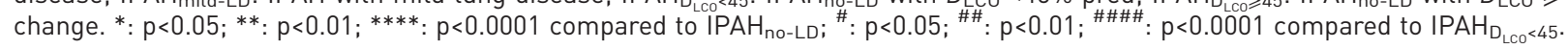

pulmonary hypertension. Mild pulmonary hypertension in the context of severe lung disease (assessed radiologically and/or spirometrically) is common, and easily ascribed to group 3 (CLD-PH). Likewise, most would agree that patients with severe pulmonary haemodynamics and severe lung disease, where the severity of pulmonary hypertension is proportionate to the degree of lung disease, also have group 3 disease. The presence of more modest lung disease in patients who fulfil traditional criteria for IPAH presents greater diagnostic and therapeutic challenges

Survival and response to therapy in IPAH mild-LD

In the current study, survival in patients with $\mathrm{IPAH}_{\text {mild-LD }}$ was significantly worse than in $\mathrm{IPAH}_{\mathrm{no}-\mathrm{LD}}$. In addition, although patients with $\mathrm{IPAH}_{\text {no-LD }}$ experienced significant improvements in walk distance and emPHasis-10 score following initiation of PAH therapies, this same improvement was not observed in

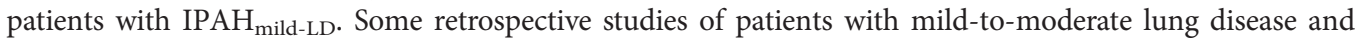
severe pulmonary hypertension have reported improved haemodynamics and exercise capacity following commencement of PAH therapies [12-14]. Conversely, BREwis et al. [15] failed to demonstrate improvement in 6-min walk distance (6MWD) or World Health Organization functional class in 118 patients with severe pulmonary hypertension and varying degrees of lung disease following PAH therapy, while we have previously reported treatment response to pulmonary vascular therapy in only $19 \%$ of patients with severe CLD-PH [16]. Prospective randomised controlled studies (RCTs) of PAH therapies in patients with CLD-PH due to COPD/emphysema have suffered from methodological weaknesses $[17,18]$ or recruited patients with mild pulmonary hypertension $[19,20]$, although VITULO et al. [21] performed a RCT in 31 patients with severe CLD-PH due to COPD and demonstrated significant improvements in pulmonary haemodynamics, but no improvement in 6MWD.

The 6th WSPH task force on CLD-PH recommended that in patients with coexisting lung disease, PAH should be diagnosed when pulmonary hypertension is moderate-severe, when only modest spirometric (i.e. $\mathrm{FEV}_{1}>60 \%$ pred and $\mathrm{FVC}>70 \%$ pred) or parenchymal abnormalities are present and when $D_{\mathrm{LCO}}$ is low with respect to obstructive or restrictive lung function [7]. Using these criteria, patients in our $\mathrm{IPAH}_{\text {mild-LD }}$ group would keep their original diagnosis of IPAH. Our observations regarding the effect that mild parenchymal lung disease has on response to therapy and survival suggests that $\mathrm{IPAH}_{\text {mild-LD }}$ is a distinct phenotype and that further prospective studies to assess treatment response in these patients are 

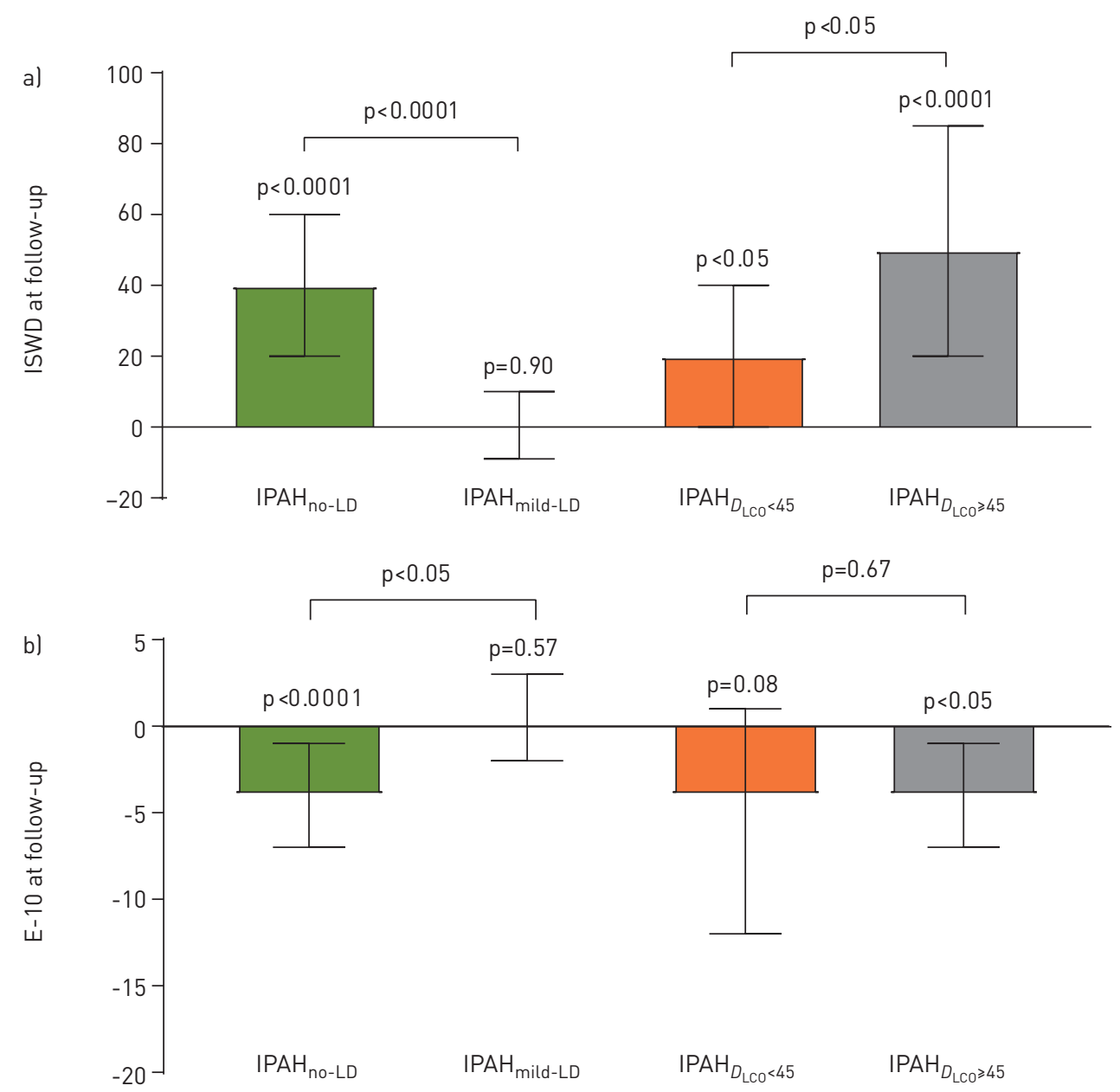

FIGURE 4 Change at first follow-up beyond 90 days in a) incremental shuttle walking test distance (ISWD); b) emPHasis-10 quality-of-life score (E-10). Data are presented as median (95\% CI). IPAH: idiopathic pulmonary arterial hypertension; IPAH no-LD: IPAH with no lung disease; IPAH mild-LD: IPAH with mild lung disease; IPAH ${ }_{D L C O<45}$ : IPAH ${ }_{\text {no-LD }}$ with diffusing capacity of the lung for carbon monoxide $\left(D_{\mathrm{LCO}}\right)<45 \%$ pred;

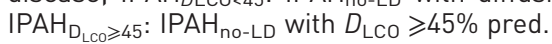

warranted. Recognition of an $\mathrm{IPAH}_{\text {mild-LD }}$ phenotype also has implications for risk stratification, decisions regarding transplantation and $\mathrm{PAH}$ therapy clinical trial design.

IPAH with $\mathrm{D}_{\text {LCO }}<45 \%$

TRIP et al. [22] observed a bimodal distribution of percentage predicted $D_{\text {LCO }}$ in a cohort of 166 patients diagnosed with IPAH, and demonstrated that a $D_{\mathrm{LCO}}<45 \%$ pred conferred worse survival. While they included patients who had mild or moderate lung disease, we observed a similar distribution of percentage predicted $D_{\text {LCO }}$ in patients without any lung disease $\left(\mathrm{IPAH}_{\mathrm{no}-\mathrm{LD}}\right.$, supplementary figure $\left.\mathrm{S} 2\right)$. Subsequently, OLSSON et al. [23] described a subgroup of patients with IPAH with no parenchymal lung disease but severely reduced gas transfer. In keeping with these two studies, our cohort of $\mathrm{IPAH}_{\text {no-LD }}$ patients with $D_{\text {LCO }}<45 \%$ pred $\left(\mathrm{IPAH}_{D \mathrm{LCO}<45}\right)$ was older, more likely to have a smoking history and had a lower exercise capacity. Although survival in patients with $\mathrm{IPAH}_{D \mathrm{LCO}<45}$ was significantly worse than those with $\mathrm{IPAH}_{\mathrm{D}_{\mathrm{LCO}} \geqslant 45}$, significant improvements in ISWD were observed following PAH therapy, unlike in patients with $\mathrm{IPAH}_{\text {mild-LD }}$. The cause of the reduced $D_{\mathrm{LCO}}$ in a proportion of IPAH patients is unclear. Pulmonary veno-occlusive disease is a rare cause of low $D_{\mathrm{LCO}}$ and is haemodynamically indistinguishable from PAH [10]. However, we excluded patients $(n=18)$ where there was a possibility of PVOD based on radiological assessment. Given the increased frequency of smoking in the $\mathrm{IPAH}_{D \mathrm{LCO}<45}$ group it is possible that the reduced $D_{\text {LCO }}$ may represent emphysema not visible on cross-sectional imaging [24]. However, tobacco smoke has also been shown to cause pulmonary vascular remodelling in animal models, and specifically to cause damage to the pulmonary capillaries [25]. Therefore, the data from the current study provide further 


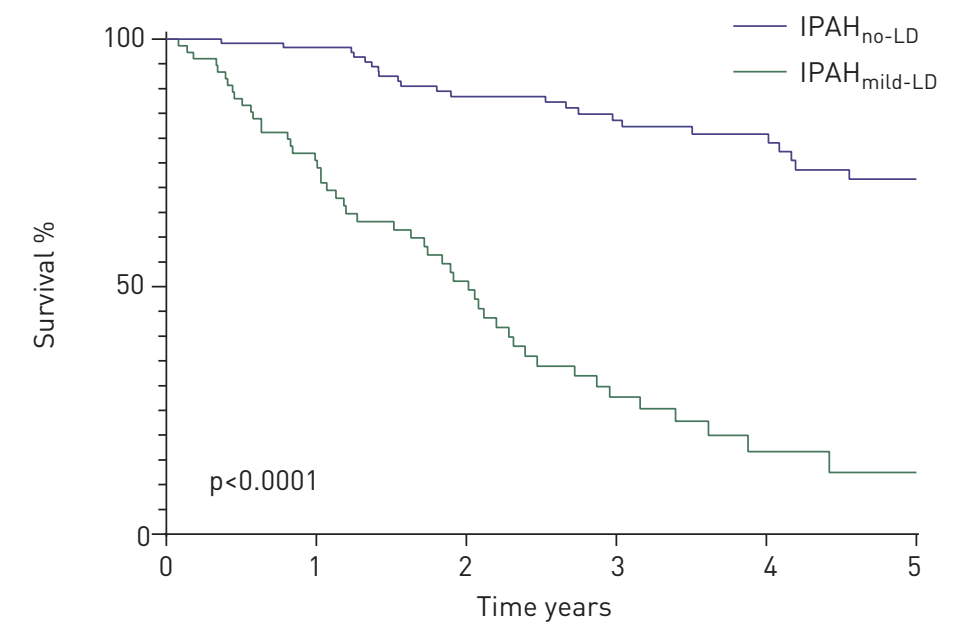

$\begin{array}{lcccccc}\text { At risk n } & & & & & & \\ \mathrm{IPAH}_{\text {no-LD }} & 125 & 106 & 80 & 65 & 46 & 32 \\ \mathrm{IPAH}_{\text {mild-LD }} & 76 & 51 & 29 & 12 & 5 & 1\end{array}$

FIGURE 5 Survival in patients with idiopathic pulmonary arterial hypertension with no lung disease (IPAH no-LD) $^{\text {) }}$ and mild lung disease (IPAH mild-LD treated with oral combination therapy within 6 months of diagnosis.

support for the existence of a vanishing capillary syndrome as proposed by HoEper et al. [26]. Further histological data are required to fully explain this phenomenon.

\section{Limitations}

This is a retrospective study and hence there were some data availability issues, including first follow-up ISWD data which was not available in $19 \%$ of patients. Patients who were unable to attempt the incremental shuttle walking test due to their pulmonary hypertension were ascribed a distance of $0 \mathrm{~m}$, which would minimise any potential bias resulting from missing data. Baseline scores for emPHasis-10 were only available for $34 \%$ of patients, since it was only introduced in our centre in 2014 . A small number of patients $(3 \%)$ with $\mathrm{IPAH}_{\text {no-LD }}$ and $\mathrm{IPAH}_{\text {mild-LD }}$ did not have spirometry available and were categorised based on CT data alone. Parenchymal lung disease assessment was based on qualitative clinical reports provided by radiologists at the time of initial diagnosis in our unit, and not on fully quantitative assessments. However, our data demonstrate that "real-world" clinical radiological assessments of the presence and extent of parenchymal lung disease can be used to identify patient groups with different outcomes. While our patients now routinely undergo high-resolution CT (HRCT) imaging and CT pulmonary angiography, some patients did not have specific HRCT imaging and so assessment of lung parenchyma in these patients may have been more limited. As there was no control group in this study, we cannot rule out a treatment effect of PAH therapies on patients with $\mathrm{IPAH}_{\text {mild-LD. }}$

\section{Conclusion}

The presence of even mild parenchymal lung disease in patients who, based on current recommendations, would be classified as having IPAH has a significant adverse effect on survival and, in this patient cohort, was associated with a lack of significant improvement in exercise capacity following treatment. Patients with the phenotype of $\mathrm{IPAH}_{\text {mild-LD }}$ can be identified using lung function testing and qualitative clinical description of the presence and extent of parenchymal lung disease on routine radiological reporting. In addition, a proportion of patients with IPAH and no evidence of lung disease or PVOD have a severely reduced diffusion capacity. Our data support the need for prospective RCTs in patients with these phenotypes to assess the effects of PAH therapies on short- and long-term outcomes.

Support statement: A.A.R. Thompson is supported by a British Heart Foundation Intermediate Clinical Fellowship (FS/ 18/13/3328). A.J. Swift is supported by a Wellcome Trust Clinical Research Career Development Fellowship (205188/Z/ 16/Z). Funding information for this article has been deposited with the Crossref Funder Registry.

Conflict of interest: R.A. Lewis reports non-financial support from Actelion Pharmaceuticals, outside the submitted work. A.A.R. Thompson reports grants from British Heart Foundation, during the conduct of the study; support for meeting attendance from Actelion Pharmaceuticals Ltd, outside the submitted work. C.G. Billings has nothing to 
disclose. A. Charalampopoulos reports grants, personal fees and non-financial support from Actelion Pharmaceuticals, personal fees and non-financial support from Novartis, grants from Bayer and GSK, outside the submitted work. C.A Elliot reports personal fees for advisory board work and lectures from Actelion Pharmaceuticals, GlaxoSmithKline and Bayer, grants from Pfizer, Actelion Pharmaceuticals and Bayer, support for meeting attendance from Bayer and Actelion Pharmaceuticals, outside the submitted work. N. Hamilton reports personal fees from MSD and Actelion, grants and personal fees from Bayer, outside the submitted work. C. Hill has nothing to disclose. J. Hurdman has nothing to disclose. S. Rajaram has nothing to disclose. I. Sabroe reports grants and personal fees for advisory board from AstraZeneca, grants from GSK, outside the submitted work. A.J. Swift has nothing to disclose. D.G. Kiely reports grants, personal fees and non-financial support from Actelion, Bayer and GSK, personal fees and non-financial support from MSD, outside the submitted work. R. Condliffe reports grants, personal fees and non-financial support from Actelion Pharmaceuticals and Bayer, grants from GSK, outside the submitted work.

\section{References}

1 Ling Y, Johnson MK, Kiely DG, et al. Changing demographics, epidemiology, and survival of incident pulmonary arterial hypertension: results from the pulmonary hypertension registry of the United Kingdom and Ireland. Am J Respir Crit Care Med 2012; 186: 790-796.

2 Simonneau G, Montani D, Celermajer DS, et al. Haemodynamic definitions and updated clinical classification of pulmonary hypertension. Eur Respir J 2019; 53: 1801913.

3 Galiè N, Humbert M, Vachiery J-L, et al. 2015 ESC/ERS Guidelines for the diagnosis and treatment of pulmonary hypertension. Eur Respir J 2015; 46: 903-975.

4 Galie N, Channick RN, Frantz RP, et al. Risk stratification and medical therapy of pulmonary arterial hypertension. Eur Respir J 2019; 53: 1801889.

5 D’Alonzo GE, Barst RJ, Ayres SM, et al. Survival in patients with primary pulmonary hypertension. Results from a national prospective registry. Ann Intern Med 1991; 115: 343-349.

6 Benza RL, Miller DP, Barst RJ, et al. An evaluation of long-term survival from time of diagnosis in pulmonary arterial hypertension from the REVEAL Registry. Chest 2012; 142: 448-456.

7 Nathan SD, Barbera JA, Gaine SP, et al. Pulmonary hypertension in chronic lung disease and hypoxia. Eur Respir J 2019; 53: 1801914.

8 Chaouat A, Bugnet AS, Kadaoui N, et al. Severe pulmonary hypertension and chronic obstructive pulmonary disease. Am J Respir Crit Care Med 2005; 172: 189-194.

9 Hurdman J, Condliffe R, Elliot CA, et al. ASPIRE registry: assessing the Spectrum of Pulmonary hypertension Identified at a REferral centre. Eur Respir J 2012; 39: 945-955.

10 Montani D, O'Callaghan DS, Savale L, et al. Pulmonary veno-occlusive disease: recent progress and current challenges. Respir Med 2010; 104: Suppl. 1, S23-S32.

11 Yorke J, Corris P, Gaine S, et al. emPHasis-10: development of a health-related quality of life measure in pulmonary hypertension. Eur Respir J 2014; 43: 1106-1113.

12 Fossati L, Müller-Mottet S, Hasler E, et al. Long-term effect of vasodilator therapy in pulmonary hypertension due to COPD: a retrospective analysis. Lung 2014; 192: 987-995.

13 Girard A, Jouneau S, Chabanne C, et al. Severe pulmonary hypertension associated with COPD: hemodynamic improvement with specific therapy. Respiration 2015; 90: 220-228.

14 Calcaianu G, Canuet M, Schuller A, et al. Pulmonary arterial hypertension-specific drug therapy in COPD patients with severe pulmonary hypertension and mild-to-moderate airflow limitation. Respiration 2016; 91: 9-17.

15 Brewis MJ, Church AC, Johnson MK, et al. Severe pulmonary hypertension in lung disease: phenotypes and response to treatment. Eur Respir J 2015; 46: 1378-1389.

16 Hurdman J, Condliffe R, Elliot CA, et al. Pulmonary hypertension in COPD: results from the ASPIRE registry. Eur Respir J 2013; 41: 1292-1301.

17 Valerio G, Bracciale P, Grazia D’Agostino A. Effect of bosentan upon pulmonary hypertension in chronic obstructive pulmonary disease. Ther Adv Respir Dis 2009; 3: 15-21.

18 Rao RS, Singh S, Sharma BB, et al. Sildenafil improves six-minute walk distance in chronic obstructive pulmonary disease: a randomised, double-blind, placebo-controlled trial. Indian J Chest Dis Allied Sci 2011; 53: 81-85.

19 Blanco I, Gimeno E, Munoz PA, et al. Hemodynamic and gas exchange effects of sildenafil in patients with chronic obstructive pulmonary disease and pulmonary hypertension. Am J Respir Crit Care Med 2010; 181: $270-278$.

20 Goudie AR, Lipworth BJ, Hopkinson PJ, et al. Tadalafil in patients with chronic obstructive pulmonary disease: a randomised, double-blind, parallel-group, placebo-controlled trial. Lancet Respir Med 2014; 2: 293-300.

21 Vitulo P, Stanziola A, Confalonieri M, et al. Sildenafil in severe pulmonary hypertension associated with chronic obstructive pulmonary disease: a randomized controlled multicenter clinical trial. J Heart Lung Transplant 2017; 36: $166-174$

22 Trip P, Nossent EJ, de Man FS, et al. Severely reduced diffusion capacity in idiopathic pulmonary arterial hypertension: patient characteristics and treatment responses. Eur Respir J 2013; 42: 1575-1585.

23 Olsson KM, Fuge J, Meyer K, et al. More on idiopathic pulmonary arterial hypertension with a low diffusing capacity. Eur Respir J 2017; 50: 1700354.

24 Kirby M, Owrangi A, Svenningsen S, et al. On the role of abnormal $\mathrm{DL}_{\mathrm{CO}}$ in ex-smokers without airflow limitation: symptoms, exercise capacity and hyperpolarised helium-3 MRI. Thorax 2013; 68: 752-759.

25 Seimetz M, Parajuli N, Pichl A, et al. Inducible NOS inhibition reverses tobacco-smoke-induced emphysema and pulmonary hypertension in mice. Cell 2011; 147: 293-305.

26 Hoeper MM, Vonk-Noordegraaf A. Is there a vanishing pulmonary capillary syndrome? Lancet Respir Med 2017; 5: 676-678. 